\title{
A Cost-Benefit Analysis of Bipolar TURP for the Treatment of Bladder Outflow Obstruction
}

\author{
Giacomo Maria Pirola (D) \\ Martina Maggi ${ }^{2}$ \\ Daniele Castellani ${ }^{3}$ \\ Alessandro Sciarra ${ }^{2}$ \\ Emanuele Rubilotta ${ }^{4}$ \\ Marilena Gubbiotti (iD) \\ 'Department of Urology, San Donato \\ Hospital, Arezzo, Italy; ${ }^{2}$ Department of \\ Urology, Sapienza Rome University, \\ Policlinico Umberto I, Rome, Italy; \\ ${ }^{3}$ Department of Urology, Ospedali Riuniti \\ di Ancona, Le Marche Polytechnic \\ University, Ancona, Italy; ${ }^{4}$ Department of \\ Urology, A.O.U.I, Verona University, \\ Verona, Italy
}

\begin{abstract}
Transurethral resection of the prostate (TURP) is the gold standard surgical technique for endoscopic treatment of benign prostatic hyperplasia (BPH). Introduced in 2001, the bipolar energy appeared to be a valid alternative to the classical monopolar one with reduced risk of complication related to the use of saline irrigation and to the increased hemostatic efficacy. More recently, raising attention has been given to laser enucleation and vaporization techniques, which appear to achieve further advantages in terms of reduced hospital stay and complications compared to the resection ones. Few studies have investigated the cost/benefit ratio related to these techniques. The aim of this systematic review was to analyze the cost/benefit ratio of bipolar TURP (B-TURP) compared with other endoscopic procedures.
\end{abstract}

Keywords: benign prostatic hyperplasia, transurethral resection of the prostate, bipolar TURP, bladder obstruction

\section{Introduction}

Benign prostatic hyperplasia (BPH) is a common disease in elderly men, characterized by a combination of storage and voiding symptoms, with a progressive decreased detrusor efficacy for bladder voiding and worsening of lower urinary tract symptoms (LUTS). ${ }^{1}$ Data from a large multicentric European trial reported an overall prevalence of LUTS due to BPH of $10.3 \% .^{2}$ The prevalence rate was lowest among males aged 45-49 years (2.7\%) and increased with age until 24\% in men over 80 years. Therefore, this condition represents a major public health concern and financial burden with significative implications in terms of healthcare costs for both patients and society. ${ }^{3,4}$ After failure of medical treatment, the standard referral surgical techniques are transurethral resection of the prostate (TURP) for low- to medium-sized prostate volumes $(\mathrm{PV} ;>80 \mathrm{cc})$, or open prostatectomy (OP) for higher $\mathrm{PV}^{5-8}$

Since its first adoption in 2001, the bipolar energy appeared to improve TURP safety in comparison to monopolar TURP (M-TURP), in terms of reduced amount of delivered energy to achieve thermal cutting/ vaporization of tissue, and lower risk of TUR syndrome related to saline irrigation. ${ }^{9,10}$

In the last decade, many other technologies have been purposed and validated. The most widely used are Green Light photoselective vaporization of the prostate (PVP) and laser enucleation techniques, such as Holmium Laser Enucleation of the Prostate (HoLEP) and Thulium Laser Enucleation of the Prostate (ThuLEP). ${ }^{11,12}$ Even if these approaches have shown to achieve results comparable to the standard
Correspondence: Marilena Gubbiotti Department of Urology, San Donato Hospital, Arezzo, 52100, Italy Tel +393383910645

Email marilena.gubbiotti@gmail.com 
technique (ie, TURP) with regards to functional outcomes, only few studies have investigated the cost/ benefit ratio related to these procedures. Indeed, these innovative techniques might present an increased cost in terms of equipment and consumables. On the other hand, equipment costs may be balanced by reduced hospital stay and complication rates. ${ }^{13}$ Thus, it is crucial especially in a "costsaving" era for national healthcare systems worldwide to address this issue. The aim of this review was to analyze the cost/ benefit ratio of bipolar TURP (B-TURP) compared with other endoscopic procedures.

\section{Methods}

We systematically searched on all the electronic databases (MEDLINE, Web of Science, Cochrane Library, and Scopus) in the last twenty years for comparative trials analyzing bipolar TURP and other innovative endoscopic techniques (ie, monopolar TURP, PVP, HoLEP and ThuLEP) in terms of cost-benefit analysis. Two Authors (GMP and MM) independently screened all the papers and two other Authors (DC and ER) excluded non-pertinent articles. AS and MG supervised the overall work. We followed PRISMA criteria for systematic review, and a detailed flowchart is provided in Figure 1. A brief overview of the principal studies included in the work is provided in Table 1.

\section{Cost/ Benefit Ratio of Bipolar versus Monopolar TURP}

Despite the introduction of lasers and evolving technologies in the field of urology, transurethral resection of the prostate (TURP) is still considered the gold standard procedure for endoscopic treatment of prostatic adenoma. This has traditionally been performed by a monopolar resector that delivers energy in glycine medium, but the morbidity associated to glycine reabsorption (TURP syndrome) has led to the introduction of bipolar system. In bipolar TURP, energy is confined between electrodes at the site of the resectoscope, allowing the use of physiological irrigation medium. However, both techniques are adopted in clinical practice.

Ruiz-Deya et $\mathrm{al}^{14}$ published the first relative report in 2002. The authors reported an important cost saving with bipolar system due to saline irrigation, estimated to be $10.56 \%$ less than the monopolar approach. Although the authors did not consider the devices costs (ie, energy generators and consumables), they found an overall saving of $\$ 1138$ per patient, mostly due to the reduced likelihood of TUR syndrome or severe hematuria documented in the bipolar series.

A subsequent study by Sugihara et $\mathrm{al}^{15}$ provided relevant data from a multicentric Japanese cohort of 1531 B-TURP versus 5155 M-TURP patients. B-TURP appeared safer in terms of reduced transfusion rate (20 versus $118, p=0.018$ ), overall complications incidence (26 versus $172, p=0.001$ ), and reduced length of stay (LOS) $(7 \pm 5.0$ versus $8 \pm 4.7$ days, $p=0.003)$. Among reported complications, TUR syndrome occurred in 16 M-TURP patients versus none after B-TURP. The estimated total charge for each patient was $\$ 6062 \pm 2020$ for B-TURP versus $6103 \pm 2100$ for M-TURP $(p=0.480$, representing $1.7 \%$ reduction).

A metaanalysis (MA) by Treharne et $\mathrm{al}^{16}$ analyzed separately the main factors that provided significantly differences in clinical outcomes and that directly affected costs: TUR syndrome, blood transfusions, clot retention, and LOS. Based on UK registers, they found that overall higher equipment costs for bipolar devices were offset by saving costs from reduced LOS and lower complications. Assuming a decrease in LOS of 0.56 days from the meta-analysis, B-TURP was associated with a $£ 165.02$ reduction for LOS per patient versus M-TURP. B-TURP was also related with a $£ 71.82$ per patient reduction in complication rates, as well as a $£ 154.75$ saving per patient due to reduced readmission rate, generating an overall estimated saving of more than $£ 3.4$ million per year in the UK. A further investigated aspect was the possibility to deliver this surgery on a day-case basis. As showed, the estimated cost saving amounted of around $£ 801.00$ per patient. Therefore, B-TURP appeared more advantageous in terms of efficacy, safety and costeffectiveness than M-TURP.

\section{Cost/ Benefit Ratio of TURP versus PVP}

One of the most popular BPH laser techniques is GreenLight Prostate Laser Vaporization (PVP). As its chromophore is blood, this laser has a deep penetration into soft tissues. High power green laser energy is delivered sideways into prostate tissue, producing tissue vaporization and soft tissue ablation, with an excellent hemostatic property.

Since its introduction, PVP has emerged as a promising surgical treatment for the management of $\mathrm{BPH}$, exhibiting both efficacy and safety outcomes comparable to the standard of care (ie, TURP), with a durable response. ${ }^{17,18}$ Moreover, PVP has started to gain increasing acceptance 

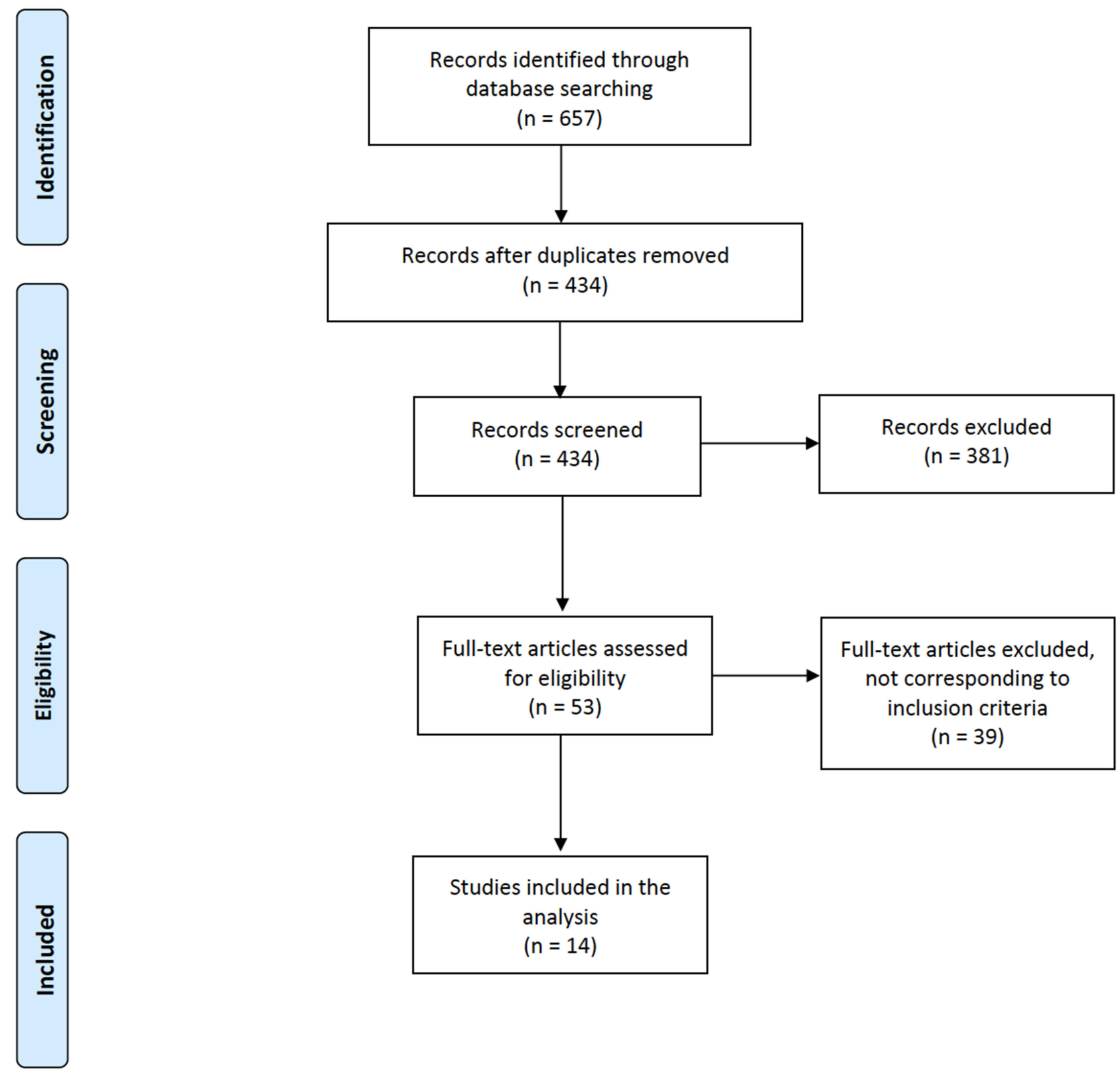

Figure I Preferred reporting items for systematic reviews and meta-analyses (PRISMA) flow diagram.

Note: Adapted from Moher D, Liberati A, Tetzlaff J, Altman DG, The PRISMA Group. Preferred Reporting Items for Systematic Reviews and Meta-Analyses: The PRISMA Statement. PLoS Med . 2009;6(7): el000097. ${ }^{36}$

worldwide due to a shorter LOS and catheterization, a faster return to stable health status, and the possibility of an outpatient surgery regimen. PVP has also demonstrated to provide real-time tissue debulking with an excellent hemostasis, even in high-risk patients and those on ongoing oral anticoagulation or antiplatelet agents. ${ }^{19,20}$ Despite these main advantages, PVP has been criticized for limited reduction of $\mathrm{PV}$, prolonged storage symptoms, and the cost of equipment and accessories. To date, only few studies have assessed a cost- effectiveness analysis comparing TURP and PVP.

Goh et al, ${ }^{21}$ analyzing the actual peri-operative hospital costs (ie, procedure and immediate peri-operative visit) of 250 patients undergoing TURP and 220 PVP in 2 private institutions in UK, found that the overall cost of TURP were significantly higher than those of PVP $(\$ 5.097 \pm \$ 5.003$ versus $\$ 4.266 \pm \$ 1.182$, respectively; $\mathrm{p}=0.01$ ). This cost difference was likely due to the higher 
Table I Summary of the Most Relevant Studies Included in This Review Comparing Cost Analysis of B-TURP with Other Techniques

\begin{tabular}{|c|c|c|c|c|c|c|}
\hline Study & Study Type & $\begin{array}{l}\text { Surgical } \\
\text { Procedures }\end{array}$ & $\begin{array}{l}\text { Number of } \\
\text { Patients } \\
\text { Involved }\end{array}$ & Main Cost-Savings Predictors & $\begin{array}{l}\text { Main Cost- } \\
\text { Savings } \\
\text { Technique }\end{array}$ & $\mathbf{p}$ \\
\hline $\begin{array}{l}\text { Ruiz-Deya } \\
2002^{14}\end{array}$ & Congress Abstract & $\begin{array}{l}\text { M-TURP vs } \\
\text { B-TURP }\end{array}$ & & $\begin{array}{l}\text { Saving of } \$ 1138 / \text { patient (reduced likelihood of } \\
\text { TUR syndrome or severe hematuria) }\end{array}$ & B-TURP & - \\
\hline Sugihara $2012^{15}$ & Retrospective & $\begin{array}{l}\text { M-TURP vs } \\
\text { B-TURP }\end{array}$ & $\begin{array}{l}5155 \\
\text { M-TURP vs } \\
\text { I53I B-TURP }\end{array}$ & $\begin{array}{l}1.7 \% \text { reduction of cost (reduced transfusion } \\
\text { rate, overall complications incidence, and LOS) }\end{array}$ & B-TURP & 0.018 \\
\hline $\begin{array}{l}\text { Treharne } \\
2018^{16}\end{array}$ & $\begin{array}{l}\text { Meta-analysis of } \\
\text { United Kingdom } \\
\text { registry (RCT) }\end{array}$ & $\begin{array}{l}\text { M-TURP vs } \\
\text { B-TURP }\end{array}$ & $\begin{array}{l}804 \text { M-TURP } \\
\text { vs } 821 \\
\text { B-TURP }\end{array}$ & $\begin{array}{l}\text { TUR syndrome; Blood; transfusions; clot } \\
\text { retention; LOS. } \\
\text { Overall estimated saving of more than } \\
£ 3.4 \text { million per year in the UK }\end{array}$ & B-TURP & $\begin{array}{l}0.006 \\
0.0003 \\
0.0161 \\
<0.0001\end{array}$ \\
\hline Goh $2010^{21}$ & Retrospective & $\begin{array}{l}\text { M-TURP vs } \\
\text { PVP }\end{array}$ & $\begin{array}{l}250 \text { M-TURP } \\
\text { vs } 220 \text { PVP }\end{array}$ & $\begin{array}{l}\text { Overall cost }(5.097 \pm \$ 5.003 \text { versus } \$ 4.266 \pm \\
\$ 1.182) \text { : reduced LOS }\end{array}$ & PVP & 0.01 \\
\hline $\begin{array}{l}\text { Bouchier-Hayes } \\
2010^{22}\end{array}$ & RCT & $\begin{array}{l}\text { M-TURP vs } \\
\text { PVP }\end{array}$ & $\begin{array}{l}59 \text { M-TURP } \\
\text { vs } 60 \text { PVP }\end{array}$ & $\begin{array}{l}\text { PVP was } 22 \% \text { cheaper than TURP due to } \\
\text { shorter LOS }\end{array}$ & PVP & $<0.005$ \\
\hline Hsu $2016^{23}$ & Retrospective & $\begin{array}{l}\text { M-TURP vs } \\
\text { PVP }\end{array}$ & $\begin{array}{l}100 \text { M-TURP } \\
\text { vs } 100 \text { PVP }\end{array}$ & $\begin{array}{l}\text { The total admission charges for PVP were } \\
\text { significantly higher than those for TURP: cost } \\
\text { equipment }\end{array}$ & TURP & $<0.001$ \\
\hline Stovsky $2006^{24}$ & Retrospective & $\begin{array}{l}\text { TURP, PVP, } \\
\text { ILC, TUNA } \\
\text { and TUMT }\end{array}$ & NR & Lower complications & PVP & NR \\
\hline Whitty $2014^{26}$ & Retrospective & $\begin{array}{l}\text { M-TURP vs } \\
\text { PVP }\end{array}$ & $\begin{array}{l}335 \text { TURP vs } \\
71 \text { PVP }\end{array}$ & $\begin{array}{l}\text { No difference after accounting for equipment, } \\
\text { training and re-intervention costs }\end{array}$ & I & I \\
\hline Caicedo $2019^{27}$ & Retrospective & $\begin{array}{l}\text { M-TURP vs } \\
\text { PVP }\end{array}$ & NR & $\begin{array}{l}\text { Complications, re- operations and re- } \\
\text { interventions }\end{array}$ & PVP & NR \\
\hline $\begin{array}{l}\text { Benejam-Gual } \\
2014^{28}\end{array}$ & Retrospective & $\begin{array}{l}\text { M-TURP vs } \\
\text { PVP }\end{array}$ & $\begin{array}{l}50 \text { M-TURP } \\
\text { vs } 48 \text { PVP }\end{array}$ & Surgical procedure (-393 Euros) & PVP & NR \\
\hline Thomas $2015^{29}$ & RCT & $\begin{array}{l}\text { M-TURP vs } \\
\text { PVP }\end{array}$ & $\begin{array}{l}\text { I33 M-TURP } \\
\text { vs } 136 \text { PVP }\end{array}$ & $\begin{array}{l}\text { When }>32 \% \text { of PVP are managed as a day case, } \\
\text { savings can be expected }\end{array}$ & PVP & NR \\
\hline Salonia $2006^{32}$ & RCT & HOLEP vs OP & $\begin{array}{l}29 \text { OP vs } 34 \\
\text { HOLEP }\end{array}$ & $\begin{array}{l}\text { reduction in blood loss, catheterization time } \\
\text { and LOS } \\
\text { Overall, the hospitalization cost of HoLEP was } \\
9.6 \% \text { less than that for OP }\end{array}$ & HOLEP & NR \\
\hline Schiavina $2020^{33}$ & Prospective & $\begin{array}{l}\text { HOLEP vs } \\
\text { TURP vs OP }\end{array}$ & $\begin{array}{l}53 \text { HOLEP vs } \\
51 \text { TURP vs } \\
47 \text { OP }\end{array}$ & $\begin{array}{l}\text { Median global cost of TURP was similar to } \\
\text { HoLEP (prostate }<70 \mathrm{~mL} \text { ) } \\
\text { Median global cost for HoLEP was found to be } \\
\text { lower than median global cost for OP (prostate } \\
>70 \mathrm{~mL} \text { ) }\end{array}$ & $\begin{array}{l}\text { No difference } \\
\text { HOLEP }\end{array}$ & $\begin{array}{l}0.61 \\
<0.001\end{array}$ \\
\hline Noble $2020^{35}$ & RCT & $\begin{array}{l}\text { TURP vs } \\
\text { ThuVARP }\end{array}$ & $\begin{array}{l}205 \text { TURP vs } \\
205 \text { ThuVARP }\end{array}$ & l & No difference & l \\
\hline
\end{tabular}

Note: Statistically significant results were $p<$ or equal to 0.01 .

Abbreviations: RCT, randomized clinical trial; B-TURP, bipolar transurethral resection of the prostate; M-TURP, monopolar transurethral resection of the prostate; LOS, length of stay; NR, not reported; PVP, GreenLight photovaporization of the prostate; ILC, interstitial laser coagulation; TUMT, transurethral thermotherapy; TUNA, transurethral needle ablation; HOLEP, holmium laser enucleation of the prostate; OP, open simple prostatectomy; ThuVARP, Thulium laser vaporesection of the prostate. 
percentage of PVP patients treated on an outpatient basis, compared to TURP patients $(95 \%$ versus $78 \%, \mathrm{p}<0.01)$. Moreover, authors found that complications that prolonged LOS, which further added expenses, were associated with TURP, yet not with PVP. Bouchier-Hayes et $\mathrm{al}^{22}$ reported similar results in a randomized trial versus TURP, in which a cost analysis has been assessed in a small subset of patients (ie, 5 cases from each group). Of note, since all cases had a standard post-operative care pathway, excessive LOS due to complications did not bias their data. Findings regarding capital cost per procedure showed that PVP was $22 \%$ cheaper than TURP (TURP \$4.277 versus PVP \$3.221), mainly due to the shorter LOS following PVP. These results were also in line with the study by Hsu et $\mathrm{al}^{23}$ who compared costs between 100 TURP and 100 PVP procedures in a single institution in China. Complication rate did not differ between the two groups, yet LOS was significantly shorter for PVP technique. However, the total admission charges for PVP were significantly higher than those for TURP, due to the higher equipment cost of the laser (ie, laser fiber); other admission charges were similar, so that Authors concluded that the only disadvantage related to PVP is the cost of the laser fiber. Stovsky et $\mathrm{al}^{24}$ estimated the economic burden for 5 different surgical procedures for BPH (ie, TURP, PVP, ILC, TUNA and TUMT) evaluating costs of initial procedures, related complications, re- treatment and routine follow- up care over a period of 24 months. At each time interval, TURP showed higher estimated costs per patient than PVP (eg, 6 months: TURP $\$ 4.030$ versus PVP \$3.020; 24 months: TURP \$4.927 versus PVP $\$ 3.589$ ). According to sensitivity analysis, PVP re- treatment rate at which the cost of PVP would be equal to that of TURP was $17 \%$, which is higher than rates reported in the literature. ${ }^{25}$ Since PVP showed lower complications and re- treatment rates, Authors concluded that the economic benefit of PVP mainly derived from these aspects. Equivocal findings have been reported in the study by Whitty et $\mathrm{al}^{26}{ }^{26}$ in which the estimated costs of TURP and PVP have been modeled using a decision- analytic model based on a cost- minimization approach in a realworld setting in an Australian public institution, reporting no significant difference in costs between the two groups. According to their base- case analysis (ie, equipment, training and re-intervention costs) on 335 TURP and 71 PVP patients, PVP was found to cost AU\$ 739 more per patient than TURP, yet sensitivity analyses performed excluding equipment and training costs, or on data from the most favorable hospital, found PVP as less costly. These results could be partially explained by the fact that PVP data were obtained during its initial implementation in clinical practice suggesting that, after a proper establishment in clinical practice, PVP could be a cost saving procedure. More recently, Caicedo et $\mathrm{al}^{27}$ carried out an economic evaluation using cost- utility ratio of TURP versus PVP, which accounted for surgical procedures, complications, re- operations and re- interventions (ie, interventions due to prostate re- growth and complications related to the initial procedure, respectively). Costs for PVP resulted to be US $\$ 979.62$ more than for TURP, yet PVP was more cost- effective than TURP. Furthermore, at both deterministic and probabilistic sensitivity analyses PVP appeared as the most expensive yet also the most efficacious procedure. Similarly, in the study by Benejam-Gual et $\mathrm{al}^{28}$ a cost- utility analysis has been conducted, evaluating costs associated with TURP and PVP procedures, complications, and re- interventions, during a 24 months period. According to this analysis, PVP was slightly more efficacious, yet also cheaper than TURP (difference of total cost per patient= -393 euros). In this series, the main determinant of costs was associated with the surgical procedure. Of note, Authors found that the post-operative phase was responsible for this cost difference, which compensated for the greater PVP equipment costs. Thomas et $\mathrm{al}^{29}$ assessed estimates of costs of TURP versus PVP procedures analyzing data from three MA and GOLIATH trial, the largest RCT comparing PVP and M-TURP. According to their analysis, costs were almost equal between the two procedures. However, it was estimated that when $>32 \%$ of PVP are managed as a day case, significant savings can be expected.

\section{Cost/ Benefit Ratio of B-TURP vs Laser Enucleation Procedures}

In alternative to PVP, other laser technologies aiming to prostate enucleation rather than vaporization were largely adopted during the last 20 years. The main advantage of those techniques is that they allow a complete enucleation of the adenoma, achieving similar results to open simple prostatectomy without the comorbidity of a major surgery. The main two widespread techniques are Holmium Laser Enucleation of the Prostate (HoLEP) and Thulium Laser Enucleation of the Prostate (ThuLEP). 
First proposed by Fraundorfer and Gilling, ${ }^{30}$ laser enucleation techniques were encouraged to overcome the problem of treating large-sized adenomas $(>70 \mathrm{cc})$. The mostly widespread technique is HoLEP. Although many papers report short- and long-term functional results comparable with OP and TURP, a relative cost/ benefit analysis has not frequently been assessed.

Fraundorfer et $\mathrm{al}^{31}$ outlined a comparative costanalysis of Holmium Laser Resection of the Prostate (HoLRP) and B-TURP. Due to reduced catheterization time, reduced LOS, less risk of bleeding and reduced incidence of complications observed following HoLRP, while offering equivalent functional outcomes, HoLRP showed a $24.5 \%$ cost savings over TURP, when inhospital and post-discharge events were analyzed.

Salonia et $\mathrm{al}^{32}$ firstly provided an immediate- and short-term cost comparison between HoLEP and OP. The significant reduction in blood loss, catheterization time and LOS in the HoLEP group appeared to be more costeffective than the relatively higher operative time (contributing an average of $25.1 \%$ to the cost of HoLEP) and instrumentation costs of the laser technique. Moreover, the cost of laser fibers (that allows at least 10 utilizations) was aligned with the disposable costs of the TURP loops.

A study by Schiavina et $\mathrm{al}^{33}$ compared the overall costs of HoLEP, TURP and OP among a large series of BPH patients. Even if all the three techniques appeared to achieve similar results in terms of symptoms relief, there were significant differences in terms of costs. Operative room usage, anesthesiology and disposable products' costs revealed to be significantly higher for HoLEP in prostate glands $\leq 70 \mathrm{cc}$, when compared to those treated with TURP ( $\mathrm{p} \leq 0.001$ ), with a difference in median direct costs of $866.62 €$ versus $650.90 €$. However, indirect costs related to hospital stay were inferior for HoLEP, thus the median global cost of TURP was similar to HoLEP (2151.69€ versus 2185.61€, respectively; $\mathrm{p}=0.61$ ). On the other hand, considering patients with $\mathrm{PV}>70 \mathrm{cc}$, median global cost for HoLEP was found to be lower than median global cost for OP (2174.15€ versus $4064.97 €$, respectively; $\mathrm{p} \leq 0.001$ ).

The other main laser enucleation technique is ThuLEP. For its physical properties, Thulium laser achieves both enucleation and vaporization of prostatic tissue, therefore it should be considered also in terms of Vapoenucleation (ThuVEP) or Vaporesection (ThuVARP). ${ }^{34}$

Noble et $\mathrm{al}^{35}$ presented in 2020 a cost-comparison analysis between TURP and ThuVARP whit data from the UK-UNBLOCS study, which is a multicentric UK clinical trial designed to assess the clinical comparison between B-TURP and ThuVEP in 410 patients. The total adjusted mean costs in the TURP arm resulted similar to the ThuVARP arm ( $£ 4244$ versus $£ 4252$ ), with a cost difference of $£ 9$ (95\% CI: $£ 376, £ 359$ ). Authors outlined that the potential benefit of ThuVARP in terms of reduced LOS and potential to be done as a day-case did not materialise. Therefore, B-TURP is still a cost-effective procedure for BPH surgical treatment.

\section{Conclusion}

Even if only few articles have investigated the cost/ benefit ratio of surgical treatment for BPH, B-TURP still appears to be a valid option by a clinical yet also economic point of view. However, laser techniques represent a valid alternative to TURP, not only in terms of minor complications and similar functional outcomes, but also in terms of costs. Their widespread use, together with lower purchase costs, would probably make laser devices more appealing for the next generation of urologists.

\section{Disclosure}

The authors report no conflicts of interest in this work.

\section{References}

1. Lee SWH, Chan EMC, Lai YK. The global burden of lower urinary tract symptoms suggestive of benign prostatic hyperplasia: a systematic review and meta-analysis. Sci Rep. 2017;7(1):7984. doi:10.1038/s41598-017-06628-8

2. Verhamme KM, Dieleman JP, Bleumink GS, et al. Triumph Pan European Expert Panel. Incidence and prevalence of lower urinary tract symptoms suggestive of benign prostatic hyperplasia in primary care-the Triumph project. Eur Urol. 2002;42(4):323-328. doi:10.1016/ S0302-2838(02)00354-8

3. Wei JT, Calhoun E, Jacobsen SJ. Urologic diseases in America project: benign prostatic hyperplasia. J Urol. 2008;179:S75-80. doi:10.1016/j. juro.2008.03.141

4. Kirk D, McNicholas TA. Benign prostatic hyperplasia: counting the cost of its management. BJU Int. 2010;106(4):586. doi:10.1111/j.1464410X.2010.09551_2.X

5. Busetto GM, Del Giudice F, D'Agostino D, et al. Efficacy and safety of Finasteride (5 alpha-reductase inhibitor) monotherapy in patients with benign prostatic hyperplasia: a critical review of the literature. Arch Ital Urol Androl. 2020;91(4):205-210. doi:10.4081/ aiua.2019.4.205

6. Fusco F, Creta M, Trama F, et al. Tamsulosin plus a new complementary and alternative medicine in patients with lower urinary tract symptoms suggestive of benign prostatic hyperplasia: results from a retrospective comparative study. Arch Ital Urol Androl. 2020;92(3). doi:10.4081/aiua.2020.3.173

7. Califano G, Collà Ruvolo C, Creta M, et al. Focus on Silodosin: pros and Cons of Uroselectivity. Res Rep Urol. 2020;23(12):669-672.

8. Gratzke C, Bachmann A, Descazeaud A, et al. EAU guidelines on the assessment of non-neurogenic male lower urinary tract symptoms including benign prostatic obstruction. Eur Urol. 2015;67:1099-1109. doi:10.1016/j.eururo.2014.12.038 
9. Botto H, Lebret T, Barré P, Orsoni JL, Hervé JM, Lugagne PM. Electrovaporization of the prostate with the Gyrus device. $J$ Endourol. 2001;15(3):313-316. doi:10.1089/089277901750161917

10. Smith D, Khoubehi B, Patel A. Bipolar electrosurgery for benign prostatic hyperplasia: transurethral electrovaporization and resection of the prostate. Curr Opin Urol. 2005;15(2):95-100. doi:10.1097/01. mou.0000160623.13366.e8

11. Foster HE, Barry MJ, Dahm P, et al. Surgical Management of Lower Urinary Tract Symptoms Attributed to Benign Prostatic Hyperplasia: AUA Guideline. J Urol. 2018;200(3):612-619. doi:10.1016/j. juro.2018.05.048

12. Busetto GM, Del Giudice F, Maggi M, et al. Surgical blood loss during holmium laser enucleation of the prostate (HoLEP) is not affected by short-term pretreatment with dutasteride: a double-blind placebo-controlled trial on prostate vascularity. Aging (Albany NY). 2020;12(5):4337-4347. doi:10.18632/aging.102883

13. Salciccia S, Del Giudice F, Maggi M, et al. Safety and Feasibility of Outpatient Surgery in Benign Prostatic Hyperplasia: a Systematic Review and Meta-Analysis. J Endourol. 2021;35(4):395-408. doi:10.1089/end.2020.0538

14. Ruiz-Deya G, Hellstrom W, Thomas R. Minimally invasive treatment of BPH using a novel electrocautery system (Gyrus): a retrospective financial analysis versus standard monopolar resection. $J$ Endourol. 2002;16(Suppl 1):A25.

15. Sugihara T, Yasunaga H, Horiguchi $H$, et al. In-hospital outcomes and cost assessment between bipolar versus monopolar transurethral resection of the prostate. J Endourol. 2012;26(8):1053-1058. doi:10.1089/end.2011.0592

16. Treharne C, Crowe L, Booth D, Ihara Z. Economic Value of the Transurethral Resection in Saline System for Treatment of Benign Prostatic Hyperplasia in England and Wales: systematic Review, Meta-analysis, and Cost-Consequence Model. Eur Urol Focus. 2018;4(2):270-279. doi:10.1016/j.euf.2016.03.002

17. Bachmann A, Tubaro A, Barber N. 180-W XPS GreenLight laser vaporisation versus transurethral resection of the prostate for the treatment of benign prostatic obstruction: 6-month safety and efficacy results of a European Multicentre Randomised Trial--the GOLIATH study. Eur Urol. 2014;65(5):931-942. doi:10.1016/j.eururo.20 13.10.040

18. Thomas JA, Tubaro A, Barber N. A Multicenter Randomized Noninferiority Trial Comparing GreenLight-XPS Laser Vaporization of the Prostate and Transurethral Resection of the Prostate for the Treatment of Benign Prostatic Obstruction: two-yr Outcomes of the GOLIATH Study. Eur Urol. 2016;69(1):94-102. doi:10.1016/j. eururo.2015.07.054

19. Kumar N, Vasudeva P, Kumar A, Singh H. Prospective Randomized Comparison of Monopolar TURP, Bipolar TURP and Photoselective Vaporization of the Prostate in Patients with Benign Prostatic Obstruction: 36 Months Outcome. Low Urin Tract Symptoms. 2018;10(1):17-20. doi:10.1111/luts.12135

20. Mordasini L, Di Bona C, Klein J, Mattei A, Wirth GJ, Iselin CE. 80W GreenLight Laser Vaporization Versus Transurethral Resection of the Prostate for Treatment of Benign Prostatic Obstruction: 5-Year Outcomes of a Single-center Prospective Randomized Trial. Urology. 2018;116:144-149. doi:10.1016/j.urology.2018.01.037

21. Goh AC, Gonzalez RR. Photoselective laser vaporization prostatectomy versus transurethral prostate resection: a cost analysis. $J$ Urol. 2010;183(4):1469-1473. doi:10.1016/j.juro.2009.12.020

22. Bouchier-Hayes DM, Van appledorn S, Bugeja $P$, Crowe $H$, Challacombe B, Costello AJ. A randomized trial of photoselective vaporization of the prostate using the $80-\mathrm{W}$ potassium-titanylphosphate laser vs transurethral prostatectomy, with a 1-year follow-up. BJU Int. 2010;105(7):964-969. doi:10.1111/j.1464410X.2009.08961.x
23. Hsu YC, Lin YH, Chou CY. Economic Evaluation Study (Cheer Compliant) Laser Prostatectomy for Benign Prostatic Hyperplasia: outcomes and Cost-effectiveness. Medicine (Baltimore). 2016;95(5): e2644. doi:10.1097/MD.0000000000002644

24. Stovsky MD, Griffiths RI, Duff SB. A clinical outcomes and cost analysis comparing photoselective vaporization of the prostate to alternative minimally invasive therapies and transurethral prostate resection for the treatment of benign prostatic hyperplasia. $J$ Urol. 2006;176(4 Pt 1):1500-1506. doi:10.1016/j.juro.2006.06.064

25. Miki T, Kojima Y, Nonomura N, et al. Transurethral visual laser ablation of the prostate for benign prostatic hyperplasia using a KTP/YAG laser. Int $J$ Urol. 1997;4(6):576-579. doi:10.1111/ j.1442-2042.1997.tb00312.x

26. Whitty JA, Crosland P, Hewson K, et al. A cost-minimisation analysis comparing photoselective vaporisation (PVP) and transurethral resection of the prostate (TURP) for the management of symptomatic benign prostatic hyperplasia (BPH) in Queensland, Australia. BJU Int. 2014;113(Suppl 2):21-28. doi:10.1111/bju.12051

27. Caicedo JI, Taborda A, Robledo D, et al. Photovaporization of the prostate with GreenLight ${ }^{\mathrm{TM}}$ laser $180 \mathrm{~W}$ XPS versus transurethral resection of the prostate with monopolar energy for the treatment of benign prostatic enlargement: a cost-utility analysis from a healthcare perspective. World J Urol. 2019;37(5):861-866. doi:10.1007/s00345018-2425-1

28. Benejam-Gual JM, Sanz-Granda A, García-Miralles Grávalos R. Cost-effectiveness analysis at 2 years of surgical treatment of benign prostatic hyperplasia by photoselective vaporization of the prostate with GreenLight-Photo vaporization $120 \mathrm{~W}$ versus transurethral resection of the prostate. Actas Urol Esp. 2014;38(4):238-243. doi:10.1016/j.acuro.2013.09.012

29. Thomas JA, Tubaro A, Barber N, et al. The Continuing Story of the Cost-Effectiveness of Photoselective Vaporization of the Prostate versus Transuretheral Resection of the Prostate for the Treatment of Symptomatic Benign Prostatic Obstruction. Value Health. 2015;18 (4):376-386. doi:10.1016/j.jval.2015.04.002

30. Fraundorfer MR, Gilling PJ. Holmium:YAGlaser enucleation of the prostate combined with mechanical morcellation: preliminary results. Eur Urol. 1998;33(1):69-72. doi:10.1159/000019535

31. Fraundorfer MR, Gilling PJ, Kennett KM, Dunton NG. Holmium laser resection of the prostate is more cost effective than transurethral resection of the prostate: results of a randomized prospective study. Urology. 2001;57(3):454-458.

32. Salonia A, Suardi N, Naspro R, et al. Holmium laser enucleation versus open prostatectomy for benign prostatic hyperplasia: an inpatient cost analysis. Urology. 2006;68(2):302-306. doi:10.1016/j. urology.2006.02.007

33. Schiavina R, Bianchi L, Giampaoli M, et al. Holmium laser prostatectomy in a tertiary Italian center: a prospective cost analysis in comparison with bipolar TURP and open prostatectomy. Arch Ital Urol Androl. 2020;92(2). doi:10.4081/aiua.2020.2.82

34. Castellani D, Pirola GM, Pacchetti A, Saredi G, Dellabella M. State of the Art of Thulium Laser Enucleation and Vapoenucleation of the Prostate: a Systematic Review. Urology. 2020;136:19-34. doi:10.1016/j.urology.2019.10.022

35. Noble SM, Ahern AM, Worthington J, et al. The cost-effectiveness of transurethral resection of the prostate vs thulium laser transurethral vaporesection of the prostate in the UNBLOCS randomised controlled trial for benign prostatic obstruction. BJU Int. 2020;126 (5):595-603. doi:10.1111/bju.15138

36. Moher D, Liberati A, Tetzlaff J, Altman DG, The PRISMA Group. Preferred Reporting Items for Systematic Reviews and MetaAnalyses: The PRISMA Statement. PLoS Med. 2009;6(7): e1000097. https://doi.org/10.1371/journal.pmed.1000097 


\section{Publish your work in this journal}

Research and Reports in Urology is an international, peer-reviewed, open access journal publishing original research, reports, editorials, reviews and commentaries on all aspects of adult and pediatric urology in the clinic and laboratory including the following topics: Pathology, pathophysiology of urological disease; Investigation and

Submit your manuscript here: https://www.dovepress.com/research-and-reports-in-urology-journal treatment of urological disease; Pharmacology of drugs used for the treatment of urological disease. The manuscript management system is completely online and includes a very quick and fair peer-review system, which is all easy to use. Visit http://www.dovepress.com/ testimonials.php to read real quotes from published authors. 